\title{
The Paradox of Public Space: Chapter 91 and Clean Water Act 303(d)
}

\author{
DAN ADAMS \\ Northeastern University
}

\author{
MARIE LAW ADAMS \\ Massachusetts Institute of Technology
}

\begin{abstract}
An increasing challenge for the design of public space is the expanding awareness of the many dimensions and networks throughwhichthepublicdomainisfullyglobalandunbounded while built architectural projects remain inherently discrete and locally bounded - a paradox of public space-for designers. For example- how we are increasingly aware that any local and privatized practice (like farming along the Amazon River) has both significant direct and indirect impacts on shared global resources (like Canadian fisheries) the world over.
\end{abstract}

Wherein the urbanized community of the globe is increasingly aware of the magnitude of its collective footprint, regulations and policies that are born from this environmentally expansive consciousness must be progressed. Similarly, architectural designs must be progressed that productively actualize these regulations and provide models for global responsiveness through local design.

This essay focuses on the relationship between acts of urban environmental policy and acts of design, within those policy frameworks, and how these frameworks prioritize different measures of public space. Environmental policy is essential but inherently limited, in that it can only reflect past and existing design solutions. In contrast, design is a projective endeavor that seeks to reframe the actors, relationships, and possible outcomes that policies address. To ground this relational study between policy and design, this essay looks at two built projects that were guided by two major pieces of US water related policy. Design tactics that were developed from these projects are unpacked here to understand how messy realities that result from a globally inclusive notion of the waterfront as a public space can be negotiated.

POLICY \& DESIGN: RECIPROCITY.

Our awakening to the global impact of our accumulated local actions, increasingly necessitates a sophisticated and continuously adaptable marriage between architectural design and public policy. This marriage, in many ways is especially demanded because architectural projects are most typically born from highly local interests. While specific property owners, developers, towns, and institutions have localized origins, their projects inevitably have global impacts. Therefore, policy has the critical role of requiring global impacts to be addressed in concert-with, in addition-to, or in spite-of, local interest. Architecture has the critical role of negotiating this translation in the physical domain and providing design solutions from which such environmental policies can be born.
Hugh Ferriss's 1916 NYC zoning code drawings provide direct examples of the design/policy marriage. Ferriss's drawings evaluate shadow casting by built mass on the public domain of the street. These drawings morph depictions of solar angles into buildings. Architecture and atmosphere are mutually influential. This is a localized environmental footprint - an indirect, yet calculable and structured influence between a design artifact - the building, and resultant public atmosphere - the street. Here, in simple drawings, buildings rise from the ground casting shadows and darkness and stifling the air, the design solution of stepping gives birth to vertical step back zoning policy, and going further, Ferriss speculates how the translation of such design solution into zoning policy would propagate a new architectural regime and style, and instigate a new domain of artificial urban lighting effects. Here, design allows policy, which guides design, which necessitates and adapts policy, and so on in an ever-adapting marriage of, each fueled by accommodations, innovations, and advancements for the other.

While Ferriss's work depicts the negotiation of a direct relationship between architecture and the immediately adjacent public domain, this same marriage of policy and design is necessitated between globe encompassing environmental impacts that may or may not be immediately proximate to local architectural design projects. Yet, as with Ferriss's work, such legislation only has effect if architectural counterpartsto and manifestations-of such legislations are designed to reconcile cities with vast environmental territories.

\section{POLICIES OF PUBLIC GOOD:}

\section{CHAPTER 91 \& CLEAN WATER ACT.}

Two key pieces of US water policy, the Massachusetts Public Waterfront Act of 1866 better known as Chapter 91, and the US Clean Water Act of 1972 respectively regulate access to water and water quality. Both move toward the a broader conception of public space by considering environmental footprint as extra-local. Both of these contemporary policies are descendants of the Public Trust Doctrine.

The Public Trust Doctrine derives from Roman Law and was transmitted into common law of the United States through the laws of England. The Public Trust Doctrine holds that the shores, air, and flowing water (such as the sea) are common to all, to serve the public good. 
The Public Waterfront Act of Massachusetts was first enacted in 1866 , stating that the public has fundamental rights to air, sea, and shore, and that the state is a trustee of the public's interest to these resources. It does this by regulating the use of coastal and inland waters in two ways: one is to protect areas for public access, use, and enjoyment, and the other is to protect tidelands for water-dependent uses demanded by the region, such as for water dependent industry and transportation. The preservation and allocation of these seemingly simple rights becomes complicated when situated in an urban context that is continually growing and shifting over time.

Much of Boston Massachusetts's tidelands were historically filled and made into dry land, as land was granted by the state to private maritime industries during the period of industrialization. Much of Boston has since deindustrialized, which opened the filled tidal zone for redevelopment. As part of a measure to recover the public's rights to these lands (because the region was originally inter-tidal it was inherently a public resource), Boston's Harborwalk was initiated in 1984, incrementally creating waterfront walks on the water side of commercial, residential, and open space projects which has resulted in a 47 mile walk over the last 30 years.

Such well known design responses, as harborwalks, to facilitate public access to the water, fulfills the ambition of the first part of the Public Waterfront Act- access. The second part of the Waterfront Act, which calls for the preservation of marine-dependent uses is more complicated and speaks to a different measure of publicness - public good rather than public access. Public good reflects a broader regional constituency - recognizing that not only the local coastal inhabitants of Boston have a stake in coastal rights through harborwalks and waterfront parks, but so too does the entire Commonwealth (the state), including hundreds of in-land communities that depend on marine terminals and industries.

This example map below identifies areas of Chelsea Massachusetts and East Boston that were filled tide lands (yellow lines), which is the jurisdiction of Chapter 91 and all the areas that are now preserved for maritime industrial port operations called Designated Port Areas DPA's (red lines). Because this part of the policy was only spatialized after much of Boston's deindustrialization in 1978, the policy reinforces existing environmental justice burdens that these communities already faced by prohibiting local public access to preserve regional public good. These red-lined zones now receive most of the state's petroleum, road salt, and produce. For instance, the community of Chelsea on Boston Harbor has little to no public access to its waterfront.

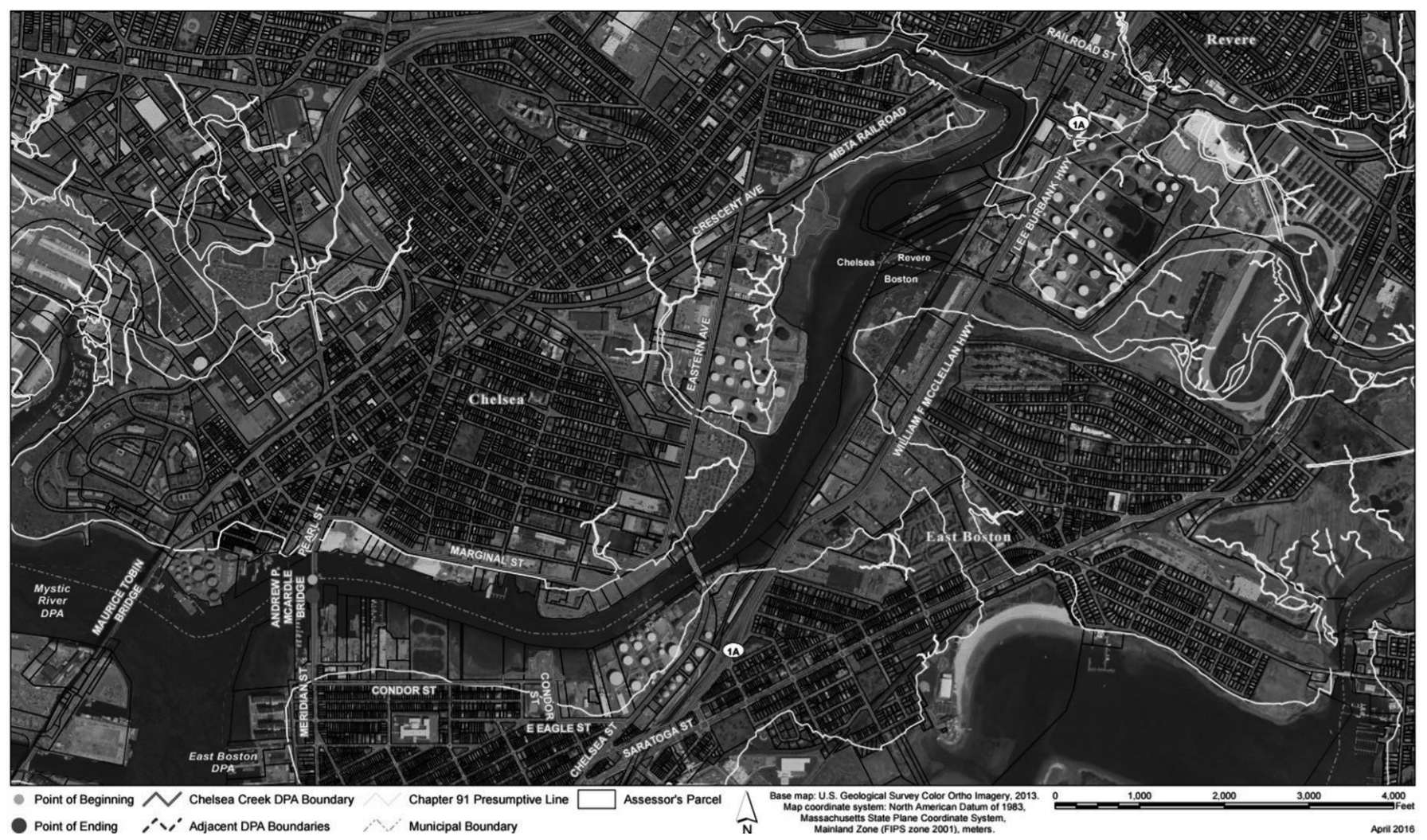

Figure 1: Chelsea MA, Chapter 91 Boundary Map \& Designated Port Area Boundary, Office of Coastal Zone Management, Department of Environmental Protection, 2018. 
Industrial port facilities, in particular, raise the distinction between public access and public good. Industrial port facilities, typically entail security protocols, safety hazards, and even environmental issues that prohibit local public access, are sometimes owned or operated by private companies, but are a central resource for providing public good to a region. While replacing such marine industrial facilities with parks might create much desired local access on the waterfront, it diminishes the regional resource networks- the public good.

A second environmental policy designed to protect a broaderscaled public good is the 'Clean Water Act', a federal law of the United States that was enacted in 1972. This law extends tenets of the Public Trust Doctrine to include the state's role in preserving water quality for the global public. The original stated objectives of the Clean Water Act established in 1972 were:

"to make all U.S. waters fishable and swimmable by 1983;" "to have zero water pollution discharge by 1985;" "to prohibit discharge of toxic amounts of toxic pollutants"1.

Achieving these objectives was undertaken by initially funding investments in municipal sewage treatment plants, setting waterways standards, and regulating pollution discharges. It goes without saying that the Clean Water Act has fallen short of fully achieving its goals. But, the Clean Water Act expanded the concept of the public space of water in the United States to be fully integrated, linking between local action (municipal discharges) and regional territories (non-municipal waterbodies) and raised consideration of the relationship between human activities and the health of marine eco-systems and water quality.

Here, the paradox of contemporary public space is raised, as the global ambitions of the Clean Water Act need to be implemented through highly local and discrete projects over time by incrementally adapting local infrastructure systems.

\section{PUBLIC ACCESS \& PUBLIC GOOD: MEASURES OF PUBLIC SPACE}

Design and policy play reciprocal roles in negotiating between local public access and regional public good. While design has a pre-policy role by offering known solutions, it also has a post-policy role of developing new typologies that expand spatial solutions around which policy can be crafted. This instigates a continually evolving cycle between policy and design, which is propelled by changing socio-cultural dynamics and environmental understanding.

One of the great proven challenges and a partial explanation of the failures for these two policies to be fully realized, is the lack of designed reconciliation between the broad ambitions of the policies and the incremental and highly localized contexts in which they must be implemented.
For example, a specific challenge for implementing the imperatives of the Clean Water Act are policies and established practices that reinforce boundaries between state or regional infrastructure operating agencies (such as departments of transportation or port authorities) and land-owning agencies (like cities, parks-departments and departments of conservation) that could best implement and maintain biolandscape based retrofits of infrastructure. For example- how park land might be best utilized to mitigate the impacts of infrastructure and industry. For example, in 1972, the same year that the US federal Clean Water Act was passed, the state of Massachusetts passed Article 97 in the Constitution of the Commonwealth of Massachusetts. This article granted citizens the right to a clean environment and authorized the Commonwealth to acquire conservation easements and was critically intended to ensure that such conservation lands were not converted to other inconsistent uses. In densifying urban environments such legislation is vital to preserve state owned public recreation lands from development. Yet, this same article also prevents the use of state owned recreation or conservation lands from being used for infrastructural purposes, such as bio-filtration or evapotranspiration of roadway run-off from highways and other infrastructural corridors. Such a link between infrastructure and park-land could, if badly designed, compromise the conservation or recreation land, and fundamentally change it from being a healthy landscape to a damaged infrastructural overflow. However, in dense urban environments, where planted environments that can perform eco-system services are rare, recreation and conservation lands can be positively designed to be multi-purpose and serve infrastructural purposes. In fact, Boston is a central precedent for such integrative practices as the city is the site of Olmsted's famed Emerald Necklace.

Article 97 in part, is an example where the failures of design, or lack of design (wherein infrastructural impacts like run-off and adjacent landscapes like wetlands, were not calibrated to the other) lead to the enactment of policies that isolate one landscape system from another. Instead of stimulating or allowing for the advancement of design to reconcile conflict, the policy establishes typological differentiations between roads and wetlands and parks, though they are inevitably integrated systems through water. Such typological boundaries simply enforce that direct relationships are prohibited, while indirect relationships persist un-designed (such as highways ultimately discharging their effluent nearby directly into a river or ocean).

Many policies are founded on and reinforce such typologicalboundaries between artifacts of the built environment. This leads architects into the position of designing equivalently typological forms- roads, or parks, or buildings- which are contracted and designed as separate things. Such environmental policies as Chapter 91 and the Clean Water Act, as well as Article 97 negotiate public good that breaches such 

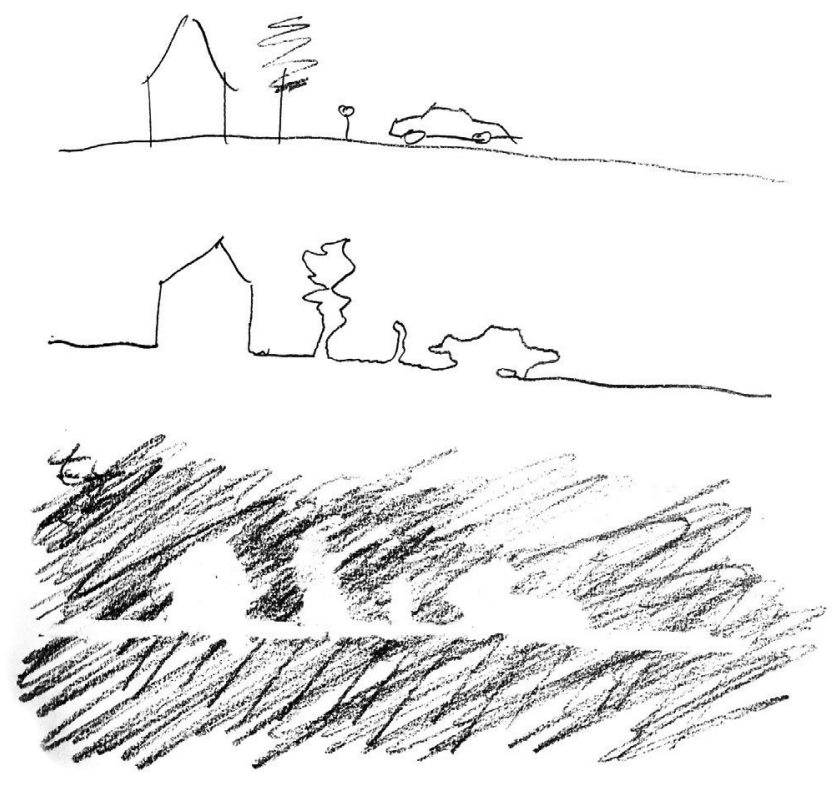

Figure 2: Typological vs. Topological Depictions of Space, Landing Studio

simplistic typological distinctions, and consequently require topologically integrative conceptions of the environment. In such a new conception architects would less design typologically isolated elements but choreograph the systems that flow across and through them as one contiguous environment - as it is.

\section{DESIGN TACTICS:}

\section{NEGOTIATING PUBLIC ACCESS AND PUBLIC GOOD}

Because policy and design have a reciprocal relationship, new design tactics that productively respond to the topologically interwoven character of the built environment are needed in order to stimulate new policy that allow for and even codify such integration.

Ferriss undertook his work through the domain of worldbuilding through drawn renderings of urban environments, in order to generate a proof of concept in isolation from other contingencies. Unlike Ferriss, the projects discussed below, follow a different strategy of experimentation by capitalizing on loop-holes that result from highly specific circumstance in order to test design ideas that have more general applicability. By achieving implementation in specific circumstances, it is then possible for the design tactics applicability and adoptability to be considered against other, less specific, circumstances.

However, like Ferriss's drawings, the new design tactics discussed below are projects that retrofit existing historic urban fabric, creating modified architectural forms to contend with new urban policy. Specifically, these projects aim to balance measures for public access and public good by spatializing or making legible the mechanisms through which these different concepts of publicness shape the urban environment. Also, each of these tactics aim to bring local public access and regional public good into dynamic tension in one space.

\section{TACTIC 1: LAYERING: REGIONAL INFRASTRUCTURE \&} LOCAL RECREATION

The P.O.R.T. is a public access landscape within road-salt dock operations of Boston Harbor. This is part of the Chapter 91 landscape declared by the state to be dedicated for maritime industrial operations to serve the commonwealth (the state). Significant tension exists here between community interests in public access to the waterfront space and the states needs for maritime delivery of salt- the good.

The design of this landscape incorporates a seasonal layering strategy to negotiate this conflict between local and regional interests, whereby landscape could be used by industrial stockpiling in winter, and public recreation in summer. The dynamic tension between regional good and public access is most palpable at the changeover seasons when salt buries the basketball court and vice-versa when salt is removed to reveal the court.

The specific loop-hole that was capitalized for this project to circumvent restrictions against industrial and recreational overlap here was the seasonality of the salt industry. This seasonality isolated recreational uses and industrial uses from each other in time. However, over the course of several years of adjacent activities, the seasonal boundary between the two uses has deteriorated as recreational uses have become interwoven into the salt operations and industrial operations have become interwoven into the park landscape. For example, each summer now a local theater group builds stages in the salt pile to support theater in the park, and each winter the park double functions as a depot for local residents to acquire buckets of salt for de-icing their home driveways and sidewalks.

\section{TACTIC 2: SYMMETRY:}

\section{MATERIAL AND FORMAL LANGUAGE}

A second project, the Infra-Space project is also in a Chapter 91 public access area, as the site was once a harbor inlet that was historically filled in to create industrial land area. This project similarly introduces local access into a regional infrastructural zone by layering public landscapes into the under-story of an elevated viaduct. While the PORT used seasonal layering 'in-time' to share the site, this project uses the physical layering of the city 'in-section'.

Further, as the storm water discharges from the highway are regulated by the Clean Water Act, this project proposes increased visibility for storm water management by bringing infrastructure typically hidden underground to the surface. Two acres of impervious watershed - the highway- previously discharged directly through underground drain pipes 

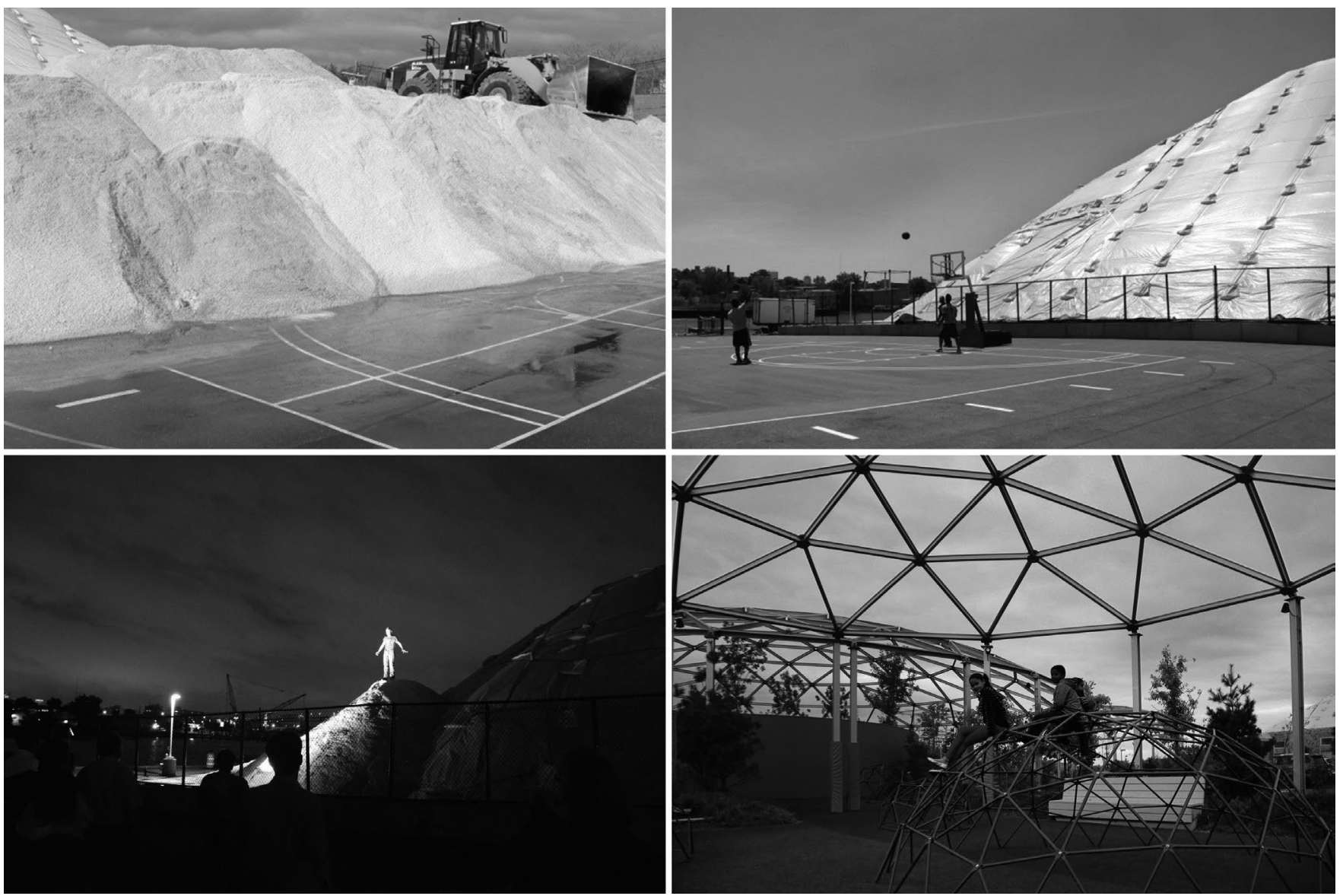

Figure 3: P.O.R.T. salt stockpiling over basketball court, summertime basketball, Hamlet on the salt pile, play domes under the oil tank domes, $2014-2017$

into Boston Harbor, which routed all the highway born contaminants directly into the sea. This project severs this direct discharge and re-routes the water into a newly constructed wetland landscape that is built beneath the elevated viaduct. While roadways and 'open-space' in the city are often typologically differentiated and regulated under different authorities, such as in Massachusetts the Department of Transportation (DOT=roadways) and the Department of Conservation and Recreation (DCR=parklands), this project introduces the loophole that the open space landscape underneath the highway was held in the jurisdiction of the DOT as an easement to perform maintenance on the highway overhead. In this specific circumstance, the under-highway landscape was not subject to Article 97, and could be developed as an infrastructural support-scape for the highway. While such interweaving of landscape uses would be typically complicated, this particularity of landscape jurisdiction allowed for the interweaving of the two. The project is now a model for other landscapes in the city, whereby pre-existing parkland is being considered for adaptation to become similar eco-system service support for mitigating infrastructural impacts.
A second design tactic that emerged in both the Infra-Space project and the P.O.R.T. was the use of consistent formal and material palettes between landscapes of infrastructure and recreation to promote an understanding of the topological continuity of environments.

The full Infra-Space design used standard Mass DOT material specifications, which were often installed in more apparent ways than typical. For example, bright turquoise PVC pipes, are common in these infrastructural landscapes, but are typically buried 'out-of-sight'. Here, these pipes are exposed as if the earth around them was excavated, and the underground pipes were revealed and the storm-water drainage system that is ubiquitously spread about the city was revealed.

The dynamic tension between regional good and public access is most direct on a boardwalk structure, a mini-viaduct under the viaduct. The majority of this public access landscape is not actually accessible as it is dedicated to managing storm water, so the boardwalk allows for movement over the ground, but prevents physical access to the ground itself. The boardwalk is detailed with mini concrete piers that echo the surrounding viaduct columns. 

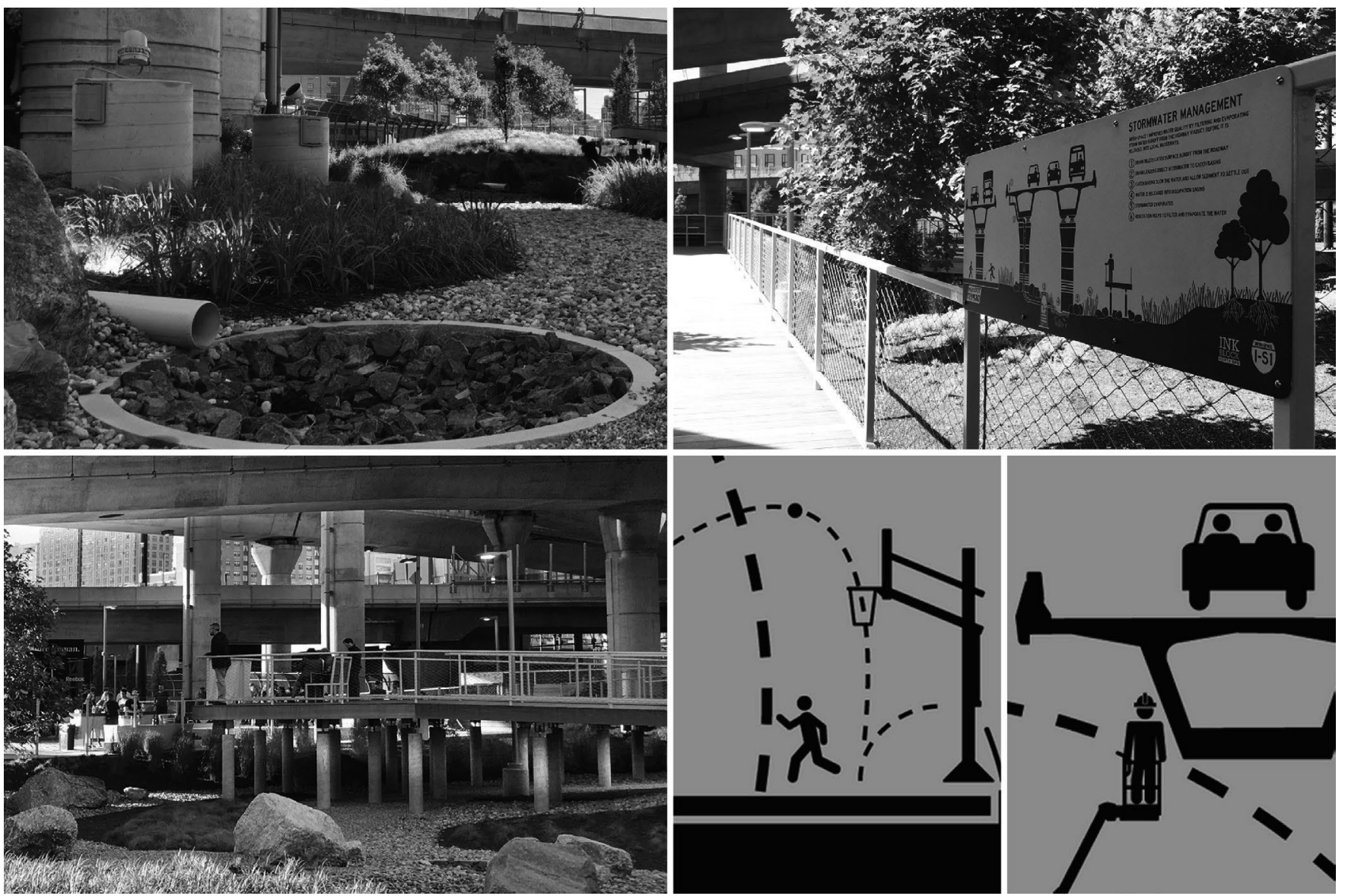

Figure 4: Infra-Space storm-water dissipation basin in the constructed wetland, informational signage of storm-water system, elevated viaduct under the elevated viaduct, basketball/maintenance signage details, 2017

Similarly, the P.O.R.T. design uses symmetries between the mound forms of the industrial and recreation landscape. This was largely a result of having the salt dock machine workers themselves build the landscape. At first, the fixed landscape elements of dirt and plants were built using the salt dock equipment and pile building expertise. Though, as described above, through the years the dock has begun building temporary salt piles for various community theater performances, furthering the blur between infrastructure and public access.

The P.O.R.T. is also assembled from pieces of a former tank farm. These pieces were re-composed as new public access components but located in context where such elements are still used for their industrial purpose. A P.O.R.T. user might be inside a former oil tank, now turned into an amphitheater, looking across the waterway at industrially active oil tanks that supply the region with fuel. Or a P.O.R.T. user might be climbing on play structures that mirror the oil tanks- creating symmetries that emphasize the interconnected relationship between the varied uses of the harbor.
TACTIC 3: TRANSPARENCY:

\section{SYSTEMS AND DISCHARGES}

The final tactic discussed here focuses on designing for transparency. Access into the landscape of regional infrastructure inherently creates legibility between scales of operation. The P.O.R.T. design brings the public into proximity with systems that are normally inaccessible, a fence-line is all that separates salt dock operations from the public access park.

At Infra-Space, the daylighting of storm-water management, that is normally buried and isolated from view, brings the function of the regionally impactful infrastructure into public consciousness. Here, the collective impact of the city's mobility and use of the viaduct becomes legible.

A final ingredient of this tactic for legibility is a consistent need for accessible explanations of the workings and intentions of these new public landscapes. As landscapes are designed to serve a public domain that may be disconnected from the site, they create unfamiliar conditions which can be illuminated. The unfamiliarity may result in part because the logics that govern the site may not result from the local scale but relate to broader regional practice. For example, 


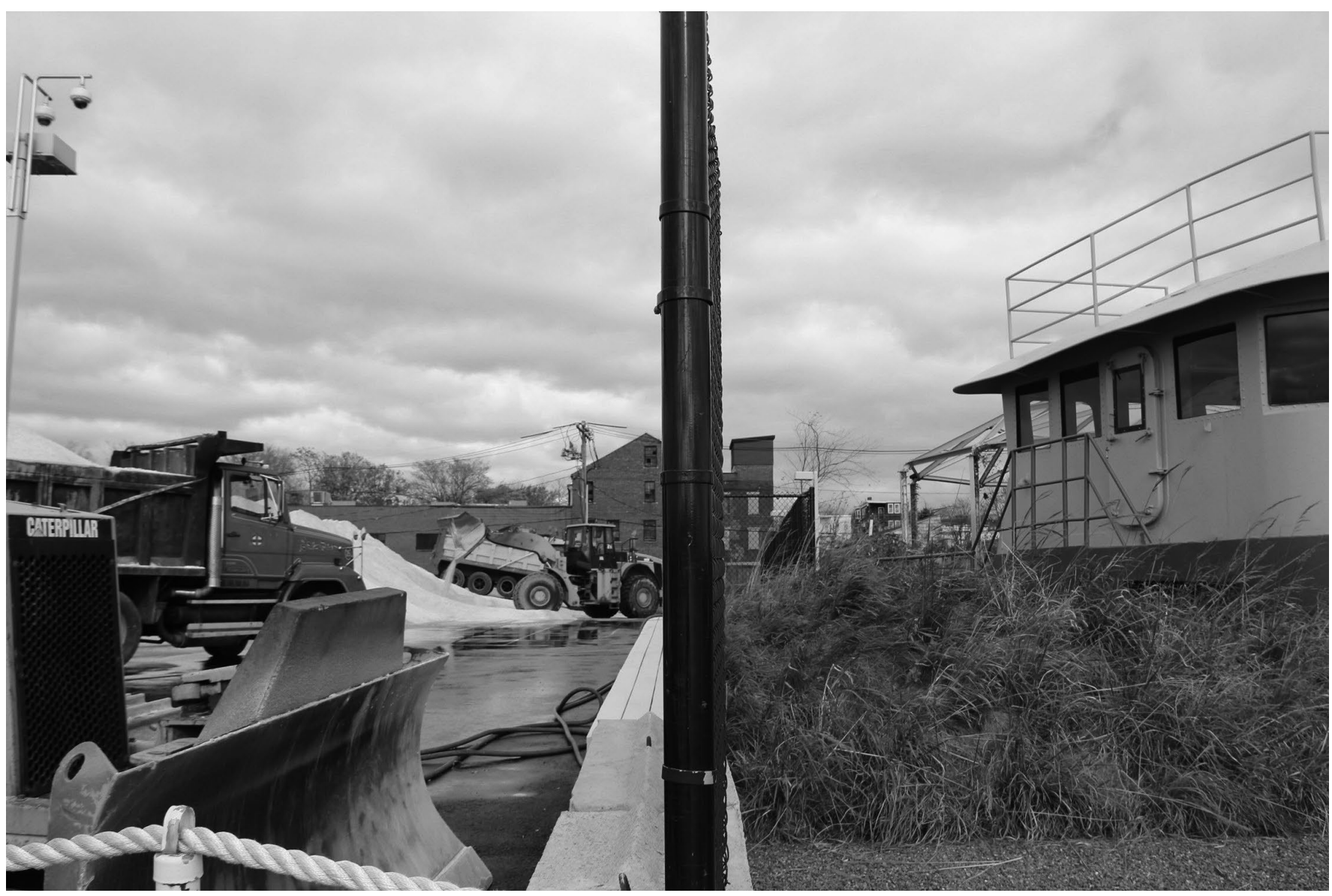

Figure 5: P.O.R.T. salt stockpiling next to public access park, 2016

how the shape of a local recreation landscape is designed to support man-lift inspections of the regional highway, more so than the basketball games played there. Oddly, through conventional typological definitions and corresponding separation of certain systems of the city from others, even everyday aspects of the cities function that are utilized by the general public are relatively unknown and mysterious. As a result, accessible signage and graphics can help make the re-introduction of these everyday yet shrouded systems more accessible and communicative.

\section{THE PARADOX OF PUBLIC SPACE}

Public space - inclusive, interconnected, vast, and accessible - is manifest in the sharing of global resources like water. To promote public 'good', policies must work across urban, political and economic boundaries. Yet, to realize this in space, these considerations must be translated into designs of the most discrete parts of the city.

\section{ENDNOTE}

1. David Keiser \& Joseph Shapiro, Consequences of the Celan ater Act and the Demand for Water Quality, Cambridge MA, National Bureau of Economic Research, 2017, 2. 